Conclusions Seventy one percent of high school students correctly identify ways of preventing the sexual transmission of HIV and who reject the major misconceptions about HIV transmission. The findings of the study indicate a need for more health education and promotion.

\section{P3.329 AWARENESS AND PREDICTORS OF USE OF FEMALE CONDOM IN THE PREVENTION OF SEXUALLY TRANSMITTED INFECTIONS IN NIGERIA}

doi:10.1136/sextrans-2013-051184.0782

${ }^{1} \mathbf{M}$ M Salawu, ${ }^{2} \mathrm{~A} 0$ Adeyemi. ${ }^{1}$ Department of Community Medicine, University College Hospital (UCH), Ibadan, Nigeria; ${ }^{2}$ National Agency for the Control of AIDS, Strategic Knowledge Management Department, Abuja, Nigeria

Background In Sub-Saharan Africa, women are disproportionally affected by HIV with more than half having HIV infection. This may be due to biological, socio-economic and other factors making them to be at higher risk of sexually transmitted infections (STIs) including HIV. Hence, there is a need for female-controlled methods against STIs. This study assessed awareness and predictors of female condom use among Nigerian women of reproductive age.

Methods Secondary analysis of data from 2007 National HIV/ AIDS and Reproductive Health Survey (NARHS) involving women of reproductive age group 15-49years was done. Multiple logistic regression was used to model for predictors of use of female condom. Results The proportion of women in the study was $46.5 \%(5,360)$. The mean age was $27.8 \pm 9.4$ years. The highest level of education was secondary education $34.9 \%$ and a higher proportion of them were from the Northwest geopolitical zone (24.9\%). The mean age at first sexual intercourse was $18.4 \pm 4.3 y$ years. About $5.5 \%$ had genital discharge in the past 12 months; $12.6 \%$ of the women had heard of female condoms and $5.7 \% \mathrm{knew}$ where to get them. However, only $0.4 \%$ had ever used female condom and $0.9 \%$ knew someone who was currently using it. Very few $(0.2 \%)$ of those that used said it felt good. Reasons for non-use were: it slipped out $0.2 \%$, made noise $0.1 \%$ and not liked $0.1 \%$. The predictors of use of female condom were age at first sexual intercourse $\leq 16$ years $\mathrm{OR}=2.095 \% \mathrm{CI}$ : 1.1-3.9; having at least secondary education $\mathrm{OR}=2.595 \% \mathrm{CI}: 1.2-$ 7.0; and sex for gift OR $=0.595 \%$ CI: $0.2-0.9$.

Conclusion Awareness and use of female condom are low among Nigerian women of reproductive age. Therefore, there is urgent need for age-specific public enlightenment and education programme on this women-centred HIV prevention strategy. This initiative is vital in multi-pronged approach towards reducing HIV risk among women.

\section{P3.330 PREVALENCE AND IMMUNOLOGICAL CORRELATES OF OPPORTUNISTIC INFECTIONS AMONG HIV PATIENTS ATTENDING AT ART CLINIC OF UNIVERSITY OF GONDAR HOSPITAL}

doi:10.1136/sextrans-2013-051184.0783

D Kifle. Addis Ababa Science and Technology University, Addis Ababa, Ethiopia

Introduction Human immunodeficiency virus (HIV) pandemic is among the greatest health crises ever faced by humanity. Morbidity and mortality in HIV disease is due to immunosuppression leading to life-threatening opportunistic infections (OIs) during the natural course of the disease.

Objective This study is aimed to assess the prevalence and CD4 correlates of OIs among HIV patients attending University of Gondar Hospital ART clinic.

Methods Institution based cross sectional study was conducted in 360 HIV patients attending the ART clinic during the study period. Current OI status of patients was determined through clinical diagnosis and laboratory investigation. Patient's CD4 count was determined using flow cytometry technique as per the FACS Calibur standard operating procedure. The data was entered and analysed using SPSS [version 16] statistical soft ware. Logistic regression analysis was done and X2 tests were used as the measure of association. Significance level of P- value less than 0.05 was used.

Results In this study, 360 HIV patients were included, of whom, $216(60 \%)$ were females. The majority of patients $(42.5 \%)$ were $25-34$ years old followed by age groups $35-44$ (34.2\%). The overall prevalence of OIs was $79(19.7 \%)$. Tuberculosis $35(9.72 \%)$ emerged as the most frequent infection to be associated with HIV infection followed by oral candidiasis $18[5 \%]$ among the spectrum of OIs observed. CD4 count less than $200 / \mathrm{mm}^{3}$ is found to have strong association with acquisition of OIs $(\mathrm{OR}=4.933, \mathrm{P}=0.000)$. Statistically significant association was also depicted between prevalence of OIs and WHO clinical stage III $(\mathrm{OR}=9.418, \mathrm{P}=0.000)$ and IV $(\mathrm{OR}=22.665, \mathrm{P}=0.000)$.

Conclusion The overall prevalence of OIs is significant $(19.7 \%)$. Tuberculosis followed by oral candidiasis and diarrhoea were the major OIs encountered by HIV patients. CD4 count less than 200/ $\mathrm{mm}^{3}$ and World Health Organization clinical stage III and IV were found to be strongly associated with acquisition of OIs.

\section{P3.331 PREVALENCE OF CHLAMYDIA TRACHOMATIS INFECTION AND ASSOCIATED FACTORS IN BRAZILIAN PREGNANT WOMEN: PRELIMINARY RESULTS OF A POPULATION- BASED STUDY}

doi:10.1136/sextrans-2013-051184.0784

M A Mesenburg, D Stauffert, M F Silveira. Universidade Federal de Pelotas, Pelotas, Brazil

Background genital infections such as Chlamydia trachomatis are a serious public health problem worldwide and are related with several negative outcomes in the pregnancy as preterm birth. In Brazil there is a growing trend in preterm birth due to several factors. Despite the probability of association with this outcome and Chlamydia trachomatis infection, there is few Brazilian populationbased studies on its prevalence and factors associated in pregnant women. This study aims to improve the knowledge about the current situation of Chlamydia trachomatis infection in pregnant women in Brazil.

Methods this is a cross-sectional study with pregnant women seen in all hospitals in the city of Pelotas, southern Brazil. Data was obtained from 361 pregnant women, bellow 30 years of age, interviewed between December 2011 and January 2013. Information on sociodemographic and behavioural factors were obtained through structured questionnaires and gestational age at delivery was obtained by medical examination. The status of Chlamydia infection was assessed by analysis of vaginal secretion, processed by Strand Displacement Amplification (SDA) BD ProbeTec ${ }^{\mathrm{TM}}$ system.

Results the prevalence of Chlamydia trachomatis infection was $15 \%$. Pregnant women without steady partners were 2.2 times more likely to test positive to Chlamydia infection. We could not find statistically significant association between Chlamydia infection and the woman's age, smoking, alcohol use, drug use and preterm birth (gestational age $\leq 36$ weeks).

Conclusion although preliminary, our results show that the prevalence of Chlamydia trachomatis among young pregnant women is high. Until the moment, we could not find association between infection and preterm birth, however it is necessary that the study be completed to better assess this relationship. Even thought our results contribute to reinforce the idea that routine test for Chlamydia trachomatis should be added to the recommended antenatal tests, at least for young pregnant women in Brazil. 